\title{
PARAMETRIC ANALYSIS OF A CONCENTRATED SOLAR RECEIVER WITH SCHEFFLER REFLECTOR
}

\section{RAMALINGAM SENTHIL, MUKUND GUPTA \& CHINMAYA RATH}

Department of Mechanical Engineering, SRM University, Kattankulathur, Chennai, India

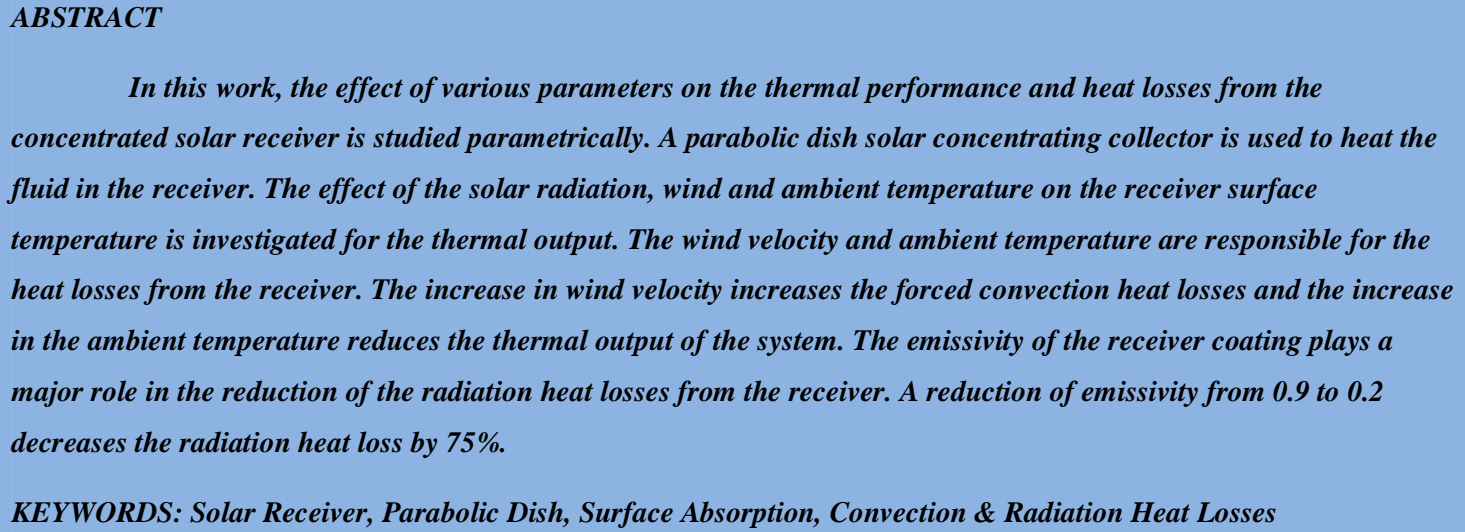

Received: Aug 25, 2017; Accepted: Sep 15, 2017; Published: Sep 28, 2017; Paper Id.: IJMPERDOCT201727

\section{INTRODUCTION}

The concentrated solar receiver is an important aspect to attain the required thermal output using the parabolic dish collector. Such receivers involve high temperatures. Hence, the attempts are to be carried out to reduce the heat losses from the receiver. The natural convective loss was determined by Jilte et al. [1] for a cylindrical cavity receiver using CFD simulations for the aperture diameters of 0.2, 0.3 and $0.4 \mathrm{~m}$ with unity aspect ratio. James et al. [2] analyzed the natural convection loss in cubical and cylindrical cavity receivers. Pyromark-2500 painted receivers were tested for operating temperatures up to $650{ }^{\circ} \mathrm{C}$. The correlations based on stagnation and convection zones were found to be fit with experimental results. Solar collector with integrated storage was discussed by several researchers [3-5]. Vinod et al. [6] analysed convective heat losses from copper coiled spherical cavity solar receiver. Kajavaliet al. [7] improved the efficiency of parabolic trough solar collector by modifying the receiver design. Flat plate collector with solar cavity covers was investigated by Lakshimapthy and Sivaraman [8]. The convection loss was reduced by $36 \%$ using quartz glass cover by Cui et al. [9]. The effect of receiver surface temperature on the thermal performance of the solar receiver is investigated y Senthil and Cheralathan through experimental and design of experiments methods [10-12]. Different high temperature solar receivers are reviewed by Senthil [13]. Energy and exergy analysis of solar receivers integrated with phase change materials are discussed [14-17].

Spiral absorber with oil, water and air is investigated thermodynamically by Pavlovic et al. [18]. Varghese et al. [19] introduced the air gap in the solar collector reduces the heat loss by $13.4 \%$ to $52.5 \%$. Design factors of parabolic dish are discussed by Hafez et al. [20]. From the literature, it is seen that improved thermal 
performance of solar receivers using a variety of receivers has been reported. The parametric study of the parabolic dish collector is carried out to predict the heat losses and the performance of the selected solar receiver. The effect of solar radiation and wind speed are discussed.

\section{PARAMETRIC ANALYSIS}

Scheffler type reflector is made up of small mirrors arranged in a paraboloidal form and the receiver is kept at a focus of $2.7 \mathrm{~m}$. The detailed specifications of the reflector are already discussed in the author's earlier works [11, 12]. The incident solar beam rays are concentrated on to the receiver. Since, the position of the sun keeps on changing; a two-way tracking system is used to maintain the focus on the receiver as shown in Figure 1. The black chrome coated steel receiver of $406 \mathrm{~mm}$ diameter is investigated and the geometrical aspects of the receiver are given in Table 1.

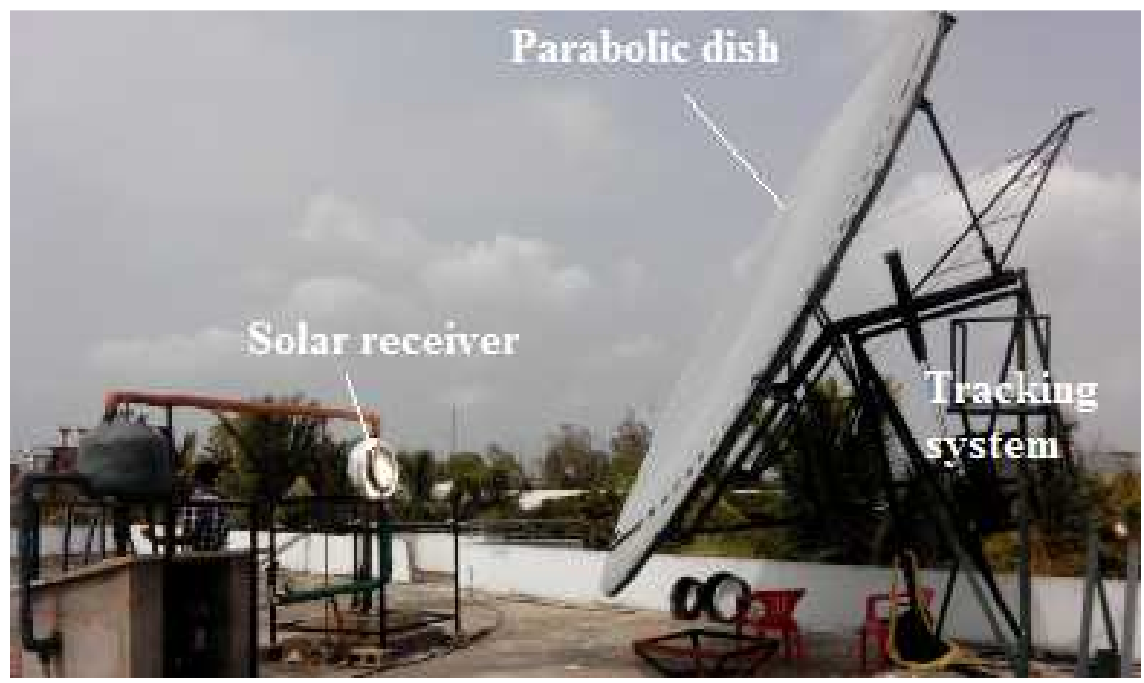

Figure 1: Scheffler Type Dish Collector and Solar Receiver

Table 1: Specifications of in the Receiver

\begin{tabular}{|l|c|}
\hline \multicolumn{1}{|c|}{ Specifications } & Values \\
\hline Surface area of the receiver surface & $0.126 \mathrm{~m}^{2}$ \\
\hline Depth of the receiver & $100 \mathrm{~mm}$ \\
\hline Material of the receiver & Mild steel \\
\hline Absorptivity of the black coating & 0.85 \\
\hline Emissivity of the black coating & 0.2 \\
\hline
\end{tabular}

The radiation heat loss depends on the receiver temperature $\left(T_{w}\right)$, effective surface area $\left(A_{t}\right)$, emissivity of surfaces $(\varepsilon)$ and ambient temperature $\left(\mathrm{T}_{\mathrm{a}}\right)$, it is expressed in eq. (1),

$$
Q_{\text {radiation }}=\sigma A_{t} \varepsilon\left(T_{w}^{4}-T_{a}^{4}\right)
$$

The free and forced convective heat losses from the cavity are calculated from the Nusselt number $(\mathrm{Nu})$ correlations for the vertical flat plate.

The convective heat transfer is expressed in eq. (2)

$$
Q_{\text {convection }}=h \cdot A_{t}\left(T_{w}-T_{a}\right)
$$




\section{RESULTS AND DISCUSSIONS}

The average receiver surface temperature is used to determine the thermal performance and heat losses. The concentration ratio is defined as the ratio of the receiver surface area of the aperture area of the reflector. Figure 2 depicts the variation of the optimum receiver surface temperature over the geometric concentration ratios. The average beam radiation considered is $800 \mathrm{~W} / \mathrm{m}^{2}$. The optimum temperature is the nominal at the given test site, and the collector with accounting the ambient conditions. Figure 3 shows the effect of solar beam radiation on the receiver surface temperature with the concentration ratio of ninety. The higher concentration ratio results in the higher receiver temperature.

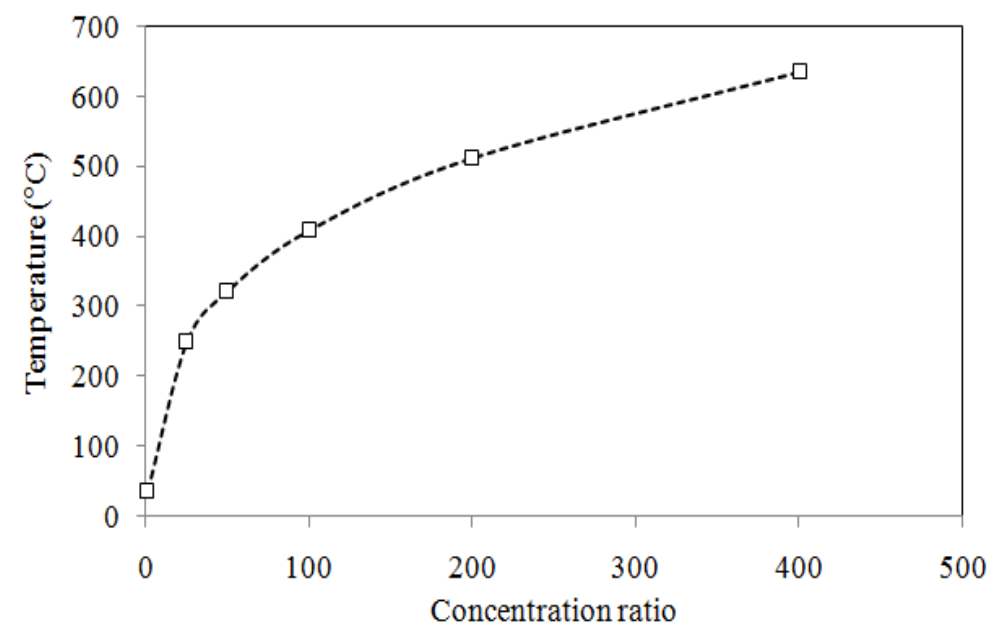

Figure 2. Effect of Concentration Ratio on the Receiver Surface Temperature At an Average Beam Solar Radiation at $800 \mathrm{~W} / \mathrm{m}^{2}$

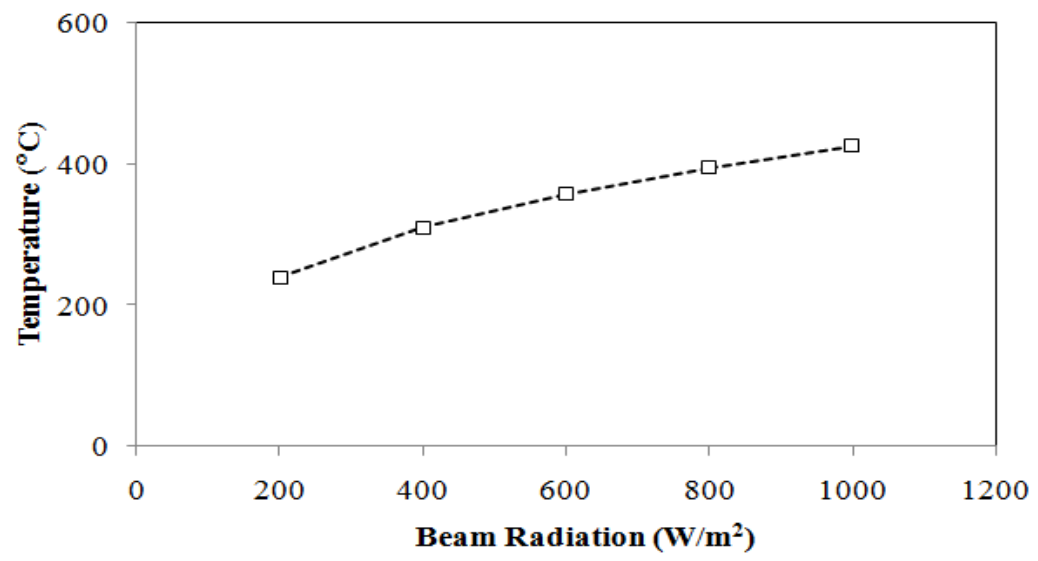

Figure 3: The Receiver Surface Temperature on the Receiver Surface at the Typical Concentration ratio of 90

The temperature increases over the receiver surface with the increase in the solar beam radiation. However, the maximum temperature obtained on the surface of the receiver depends on the fluid flow rate and wind velocity over the receiver surface. If the beam solar radiation increased from $600 \mathrm{~W} / \mathrm{m}^{2}$ to $800 \mathrm{~W} / \mathrm{m}^{2}$ produces the receiver surface temperature of 360-400 (C during the real time. 


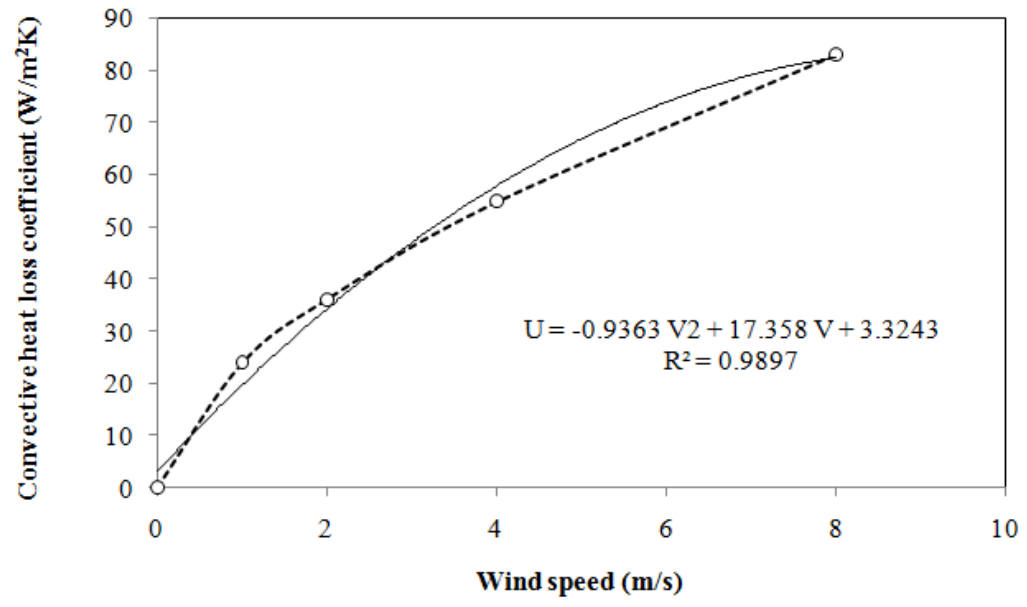

Figure 4: Convective Heat Loss Coefficient vs Wind Speed

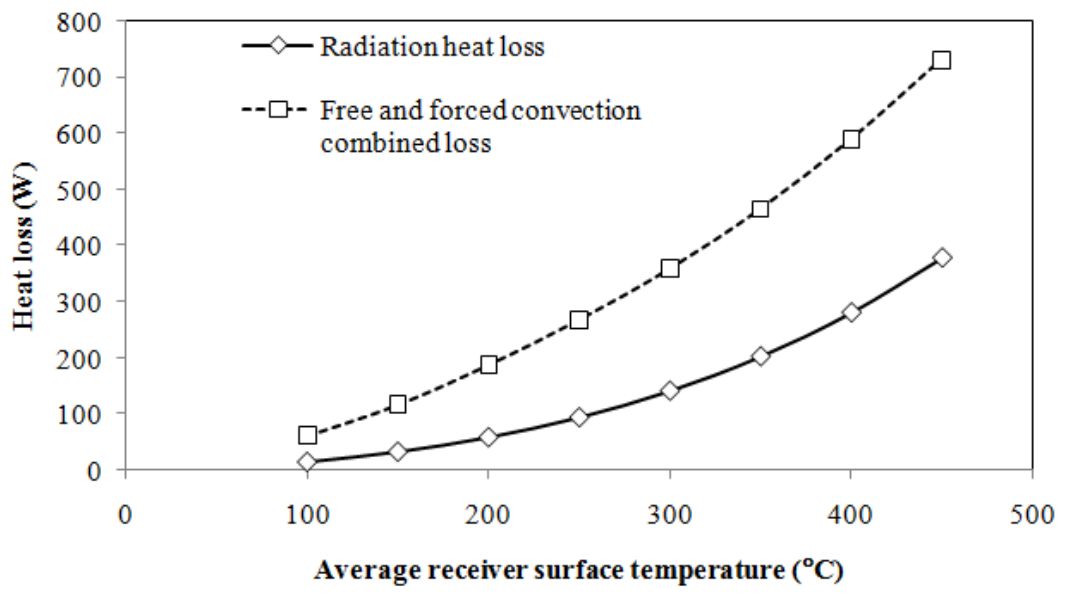

Figure 5: Heat Loss from the Receiver vs. Receiver Surface Temperature

Figure 4 and 5 show the convection heat loss coefficient and heat loss from the receiver based on the average receiver surface temperature and ambient temperature. The convection heat loss coefficient is determined from the trend as Equ. (3)

$$
h=-0.9363 V^{2}+17.358 V+3.3243, R^{2}=0.9897
$$

The convection heat transfer is more than the radiation heat transfer from the receiver surface. The low value of emissivity reduces the radiation heat losses from the receiver. The free and forced convection is considered to determine the combined heat losses. The conduction heat loss is negligible when compared to the radiation and convection. Figure 6 shows the thermal efficiency of the solar receiver based on the average receiver temperature in the ideal case of the solar receiver without wind effects. Thermal efficiency decreases with the increase in the receiver surface temperature and lies between $71 \%$ to $74 \%$. 


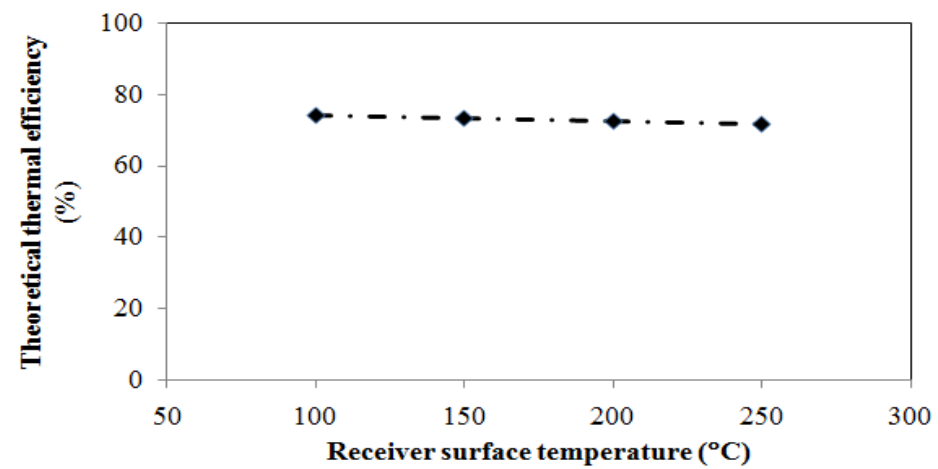

Figure 6: Thermal Efficiency of the Receiver without Wind Convection Heat Loss

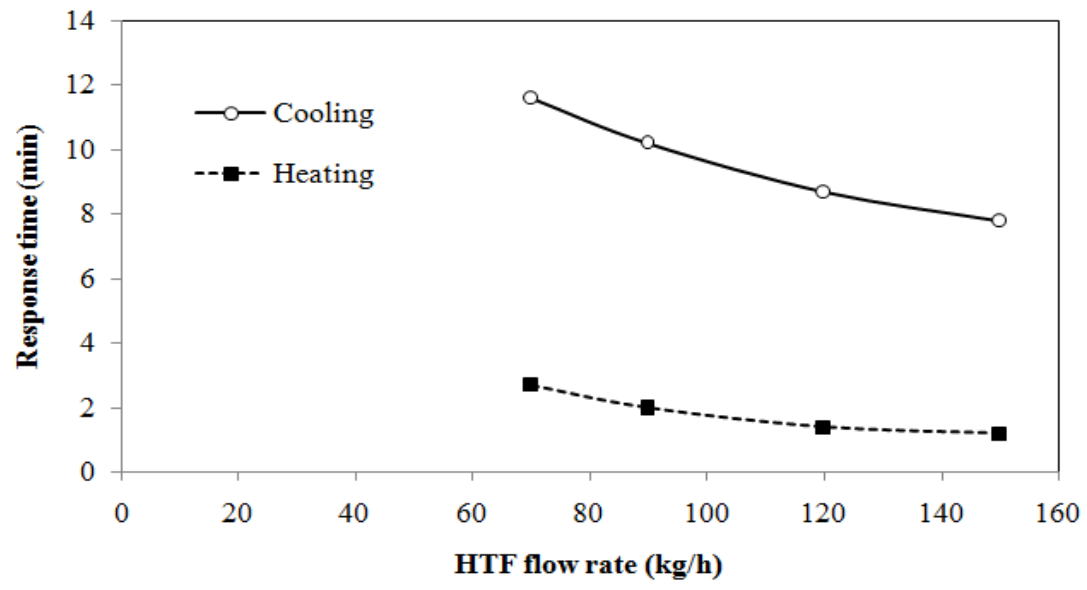

Figure 7: Response Time of the Receiver to Attain the Steady State During Cooling and Deviate from the Steady State during the Heating

Figure 7 indicates the response time of the receiver during the heating from the ambient condition and cooling the receiver by withdrawing the concentration of solar rays on to the receiver. The response time is defined as the time taken to observe the increase of water temperature by $1^{\circ}$ Celcius while heating the receiver with solar concentration. The response time of the receiver during the sudden withdrawal of the solar focus and the receiver is cooled at ambient conditions.

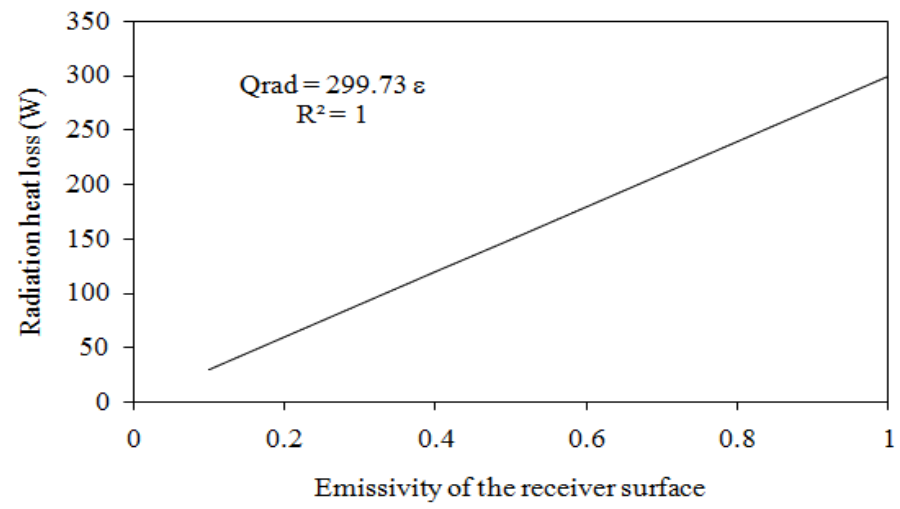

Figure 8: Radiation Heat Loss from the Receiver over the Emissivity of the Receiver Surface at the Average Receiver Surface Temperature of $200^{\circ} \mathrm{C}$

During the cooling test, the time of inlet water, leaving the receiver at the same temperature is considered as the 
response time. This is due to the thermal capacity of the receiver material and the sensible heat effect. At lower heat transfer, fluid flow rate, the heating response is more and at higher flow rates it is vice versa. The radiation heat loss is expressed for the given solar collector-receiver system as Equ. (4):

Qrad $=299.73 \varepsilon$

The radiation heat loss is reduced by $75 \%$ when the emissivity of the surfaces, reduced from 0.90 to 0.20 from Figure 8. Thus, decreasing the emissivity reduces the radiation heat losses especially. So, lower emissivity black chrome paint is preferred for the surface coating of the receiver.

\section{CONCLUSIONS}

The increase in wind velocity increases the forced convection heat losses. The increase in the ambient temperature reduces the thermal output of the system. The emissivity of the receiver coating plays an important role in the reduction of the radiation heat losses from the receiver. A reduction of emissivity from 0.9 to 0.2 decreases the radiation heat loss by 75\%. The proper insulation thickness reduced the conduction heat losses considerably and it is negligible when compared to the convection and radiation heat losses. The presented parametric analysis is useful to predict the thermal performance of the solar receiver and heat losses with respect to the ambient conditions.

\section{REFERENCES}

1. Jilte, R.D., Kedare S, B., Nayak, J.K. (2013). Natural convection and radiation heat loss from open cavities of different shapes and sizes used with dish concentrator. Mechanical Engineering Research. Vol. 3, pp.25-44.

2. James. K.Y., Clifford K Ho, Joshua M Christian (2015). Numerical simulation of natural convection in solar receivers. Journal of Solar Energy Engineering. Vol. 137 (2015), p031004.

3. A. Arunasalam, A. Ravi, B. Srivatsa, and R. Senthil. Thermal Performance Analysis on Solar Integrated Collector Storage. UARJ, 1 (2), 2012, pp.2278-1129.

4. R. Senthil and M. Cheralathan (2016). Effect of PCM in a solar receiver on thermal performance of parabolic dish collector, Thermal Science, doi: 10.2298/TSCI150730007S

5. R. Senthil and M. Cheralathan, Natural heat transfer enhancement methods in phase change material based thermal energy storage, International Journal of ChemTech Research, 9 (5), 2016, pp. 563-570.

6. Vinod. S., Prashant. D, Rupesh.G (2015). Experimental and numerical analysis of convective heat losses from spherical cavity receiver of solar concentrator. Thermal Science. Doi:10.2298/TSCI150601165S.

7. Kajavali A., B. Sivaraman and Kulasekharan N (2014). Investigation of heat transfer enhancement in a parabolic trough collector with a modified absorber. International Energy Journal 14(2014): 177-188.

8. Lakshmipathy. B, Sivaraman. B, (2016). Performance analysis on working parameters of a flat plate solar cavity collector. International Energy Journal 16 (1), pp. 1-10.

9. Fuqing Cui, Yaling He, Zedong Cheng, Yinshi Li (2013). Study on combined heat loss of a dish receiver with quartz glass cover. Applied Energy 112, pp.690 - 696.

10. Senthil, R., Cheralathan, M., (2015). Effect of non-uniform temperature distribution on surface absorption receiver in parabolic dish solar concentrator. Thermal Science. doi: 10.2298/ TSCI150609169S.

11. Ramalingam Senthil, Marimuthu Cheralathan, Effect of Once-through and Recirculated Fluid Flow on Thermal Performance 
of Parabolic Dish Solar Receiver, Indian Journal of Science and Technology, 9 (2016), 33, pp. 1-5.

12. R. Senthil, S. Prabhu and M. Cheralathan, Effect of Heat Transfer Fluid Input Parameters on Thermal Output of Parabolic Dish Solar Receiver Using Design of Experiment Techniques, International Journal of Mechanical Engineering and Technology 8(8), 2017, pp. 1148-1156.

13. R. Senthil, Recent Developments in the Design of High Temperature Solar Receivers, International Journal of Mechanical Engineering and Technology 8(8), 2017, pp. 1223-1228.

14. R. Senthil, and M. Cheralathan, Energy and exergy analysis of a parabolic dish concentrated solar receiver with integrated PCM, International Journal of Advance Research in Science and Engineering, 5 (10), 2016, pp. 117-121.

15. Jianqin Zhu, Kai Wang, Hongwei Wu, Dunjin Wang, Juan Du, A.G. Olabi, Experimental investigation on the energy and exergy performance of a coiled tube solar receiver, Applied Energy 156 (2015) 519-527.

16. R. Senthil, and M. Cheralathan, Effect of container size on thermal performance of sugar alcohol (D-Mannitol) in concentrated solar receiver, International Journal of Chemical Sciences, 14 (4), 2016, pp. 2349-2357.

17. R. Senthil, M. Cheralathan, Thermal performance of solid and liquid energy storage materials in a parabolic dish solar cooker, International Journal of Chemical Sciences 2016, 14 (4), pp. 1977-1983.

18. Sasa Pavlovic, EvangelosBellos, Willem G. Le Roux, VelimirStefanovic, Christos Tzivanidis, Experimental investigation and parametric analysis of a solar thermal dish collector with spiral absorber, Applied Thermal Engineering 121 (2017) 126-135.

19. Jaji Varghese, Samsher and K. Manjunath, A parametric study of a concentrating integral storage solar water heater for domestic uses, Applied Thermal Engineering 111 (2017) 734-744.

20. Hafez, A. Z., Ahmed Soliman, El-Metwally, K. A., and Ismail, I. M., "Design analysis factors and specifications of solar dish technologies for different systems and applications," Renewable and Sustainable Energy Reviews, 67 pp. 1019-1036, 2017. 
